\title{
CYP1A/Regucalcin Gene Expression and Edema Formation in Zebrafish Embryos Exposed to 2,3,7,8-Tetrachlorodibenzo- p-dioxin
}

\author{
Y. D. Wu · L. Jiang $\cdot$ Z. Zhou $\cdot$ M. H. Zheng • \\ J. Zhang $\cdot$ Y. Liang
}

Received: 11 August 2007/ Accepted: 11 March 2008/Published online: 10 May 2008

(C) Springer Science+Business Media, LLC 2008

\begin{abstract}
In this study, zebrafish eggs were exposed to a relatively low concentration $(50 \mathrm{pg} / \mathrm{mL})$ of $2,3,7,8$-Tetrachlorodibenzo-p-dioxin (TCDD) for $72 \mathrm{~h}$ and then transferred to vehicle/TCDD-free water for the remainder of the experiments. Mortality, heart rates, edema severity, CYP1A, and regucalcin gene expressions were investigated to study TCDD-induced toxicity in zebrafish during the early life stage. Results indicated that the $50 \mathrm{pg} / \mathrm{mL}$ TCDD caused severe and visible developmental toxicity. Further research of the long term and low concentration of TCDD exposure is required.
\end{abstract}

Keywords 2,3,7,8-Tetrachlorodibenzo-p-dioxin · Zebrafish $\cdot$ Edema $\cdot$ Gene expression

Y. D. Wu $\cdot$ J. Zhang $(\bowtie)$

Key Lab of Subtropical Agriculture and Environment, Ministry of Agriculture, Huazhong Agricultural University, Wuhan 430070, People's Republic of China

e-mail: zjie212@mail.hzau.edu.cn

Y. D. Wu

e-mail: W.Y.D_23@hotmail.com

L. Jiang $\cdot$ Z. Zhou $\cdot$ Y. Liang

School of Medicine, Jianghan University,

Hubei Province 430056, People's Republic of China

M. H. Zheng · Y. Liang ( $\square)$

State Key Laboratory of Environmental Chemistry

and Ecotoxicology, Research Center for Eco-Environmental

Sciences, Chinese Academy of Science, Beijing 100085,

People's Republic of China

e-mail: 1y76@263.net
As an unwanted byproduct, 2,3,7,8-Tetrachlorodibenzo-pdioxin (TCDD) is frequently detected in environmental samples. In 1990, whole squawfish contained detectable TCDD at all selected sample sites in Willamette River, ranging from 0.5 to $1.5 \mathrm{pg} / \mathrm{g}$ (Curtis et al. 1993). Besides, TCDD bioaccumulation by fish in Great Lakes is widespread, which indicates that fish consumption is the major pathway of exposure to human beings (Cook et al. 2003). Concerns over low concentration and long-term exposure of TCDD to fish may help to understand and commence the existing environmental situations.

TCDD caused several developmental toxic responses to teleost fish through the AHR/ARNT signaling pathway (Schmidt and Bradfield 1996), particularly the yolk sac and pericardial edema as one of the most vital responses. Likewise, the occurrence of edema in laboratory-reared larvae of wild lake trout from Lake Ontario has been linked to exposure to TCDD and structurally related compounds (Cook et al. 2003). TCDD exposure to lake trout eggs produces a dose-related induction of CYP1A in vascular endothelial cells of embryos and sac fry, which correlates with yolk sac edema, hemodynamic dysfunction, and subsequent sac fry mortality (Guiney et al. 1997). On the other hand, exposure to TCDD substantially increases the intracellular free $\mathrm{Ca}^{2+}$ level in several cell types (Puga et al. 1997; Canga et al. 1993), and regucalcin $(\mathrm{RC})$, a $\mathrm{Ca}^{2+}$-binding protein, plays a role in the maintenance of intracellular $\mathrm{Ca}^{2+}$ homeostasis by activating $\mathrm{Ca}^{2+}$ pump enzymes, was also studied in rat model to evaluate the risk posed by TCDD (Takahashi and Yamaguchi 1997; Pastorelli et al. 2006). In this study, mortality, heart rates, edema severity, CYP1A, and $\mathrm{RC}$ gene expressions were studied to investigate low dose of TCDD-induced toxicity in zebrafish during the early life stage. 


\section{Materials and Methods}

TCDD (99\% purity) dissolved in $100 \%$ DMSO was purchased from Cambridge Isotopes (Cambridge Isotope Laboratories, Andover, MA), and DMSO (AMRESCO) was used as vehicle control in all experiments.

AB-line zebrafish were raised and maintained according to the procedures described by Westerfield (1995). Embryos and juvenile fish were maintained at $26 \pm 1.5^{\circ} \mathrm{C}$ in a $14 \mathrm{~h}$ light and $10 \mathrm{~h}$ dark cycle. Newly fertilized eggs, approximately beginning at $2 \mathrm{~h}$ poster-fertilization (hpf), were exposed to vehicle ( $0.5 \%$ DMSO) or to $50 \mathrm{pg} / \mathrm{mL}$ TCDD for $72 \mathrm{~h}$ in a 6-well plate with gentle rocking. During the $72 \mathrm{~h}$ exposure time, $40 \%$ solution of each well was replaced with fresh confected reagent. Following the $72 \mathrm{~h}$ static exposure, the embryos were rinsed with water and maintained in aerating water for further observation. Each group had two parallels and experiments were repeated at least two times under the same condition. As an index of toxic responses, heart rate was determined in a $30 \mathrm{~s}$ interval using $40 \times$ microscope (Olympus, Japan). Embryos were randomly chosen in vehicle or TCDD beginning from $36 \mathrm{hpf}$, when the embryos already had heartbeats, and this was repeated every other day since then.

Edema incidence was scored as the percent of live embryos showing any discernable signs of edema at the indicated time (Henry et al. 1997). If needed, juvenile fish were anesthetized with tricaine (MS222; Sigma). The area was calculated as previously described (Prasch et al. 2004). The area of yolk sac and pericardium were determined using the area measurement function of BI 2000 Image (TME Tech Ltd, Chengdu, China). All photos were taken at $40 \times$ with the fish in a lateral orientation at the same resolution.

Using Trizol reagent (Invitrogen, Carlsbad, CA), total RNA was isolated from five zebrafish embryos selected randomly from each replicate of the control and $50 \mathrm{pg} / \mathrm{mL}$ TCDD group during three times of embryo development: 52 , 96, and $168 \mathrm{hpf}$. Then, each total RNA ( $2 \mu \mathrm{g})$ was reversetranscribed to single strand cDNA using M-MLV Reverse Transcriptase reagents (Promega UK Ltd.) according to the supplier's instructions. To detect zfCYP1A (GenBank Accession no. BC094977) and zfRC mRNA (GenBank Accession no. BC075882) expression at the three above stages, we used related primers (5'-GGAACTTCT TCA TCGTCGTG- $3^{\prime}$ and $5^{\prime}$-CATATCGTAGTATCCGTGGCT$3^{\prime}$ for ZfCYP1A, 5'-CTGGAGGATTGTCT AACCG-3' and $5^{\prime}$-CCAAAACAGCATGAAGTGA- $3^{\prime}$ for ZfRC) designed by Primer Premier 5.0 (Premier, Palo Alto, USA) to amplify a 188 base-pair (bp) fragment of the $z$ C CYP1A gene, and a $202 \mathrm{bp}$ fragment of the $z \mathrm{RC}$ gene. A denaturing step $\left(94^{\circ} \mathrm{C}\right.$, $5 \mathrm{~min}$ ) was followed by both of 35 cycles in the following conditions: denaturation $\left(94^{\circ} \mathrm{C}\right.$ for $\left.30 \mathrm{~s}\right)$, annealing $\left(56^{\circ} \mathrm{C}\right.$ for $30 \mathrm{~s}$ ), and extension $\left(72^{\circ} \mathrm{C}\right.$ for $\left.1.5 \mathrm{~min}\right)$ in $\mathrm{TC}-312$ (TECHNE). PCR products were size-fractionated in $1.5 \%$ agarose gels, stained with ethidium bromide, and measured densitometrically using JD-801 (JEDA Tech Ltd, Jiangsu, China) image software. $\beta$-Actin (GenBank Accession no. BC045846; 5'-AGCTCATAGCTCTTCTCCAG-3' and 5'CTGGTATCGTGATG GACTCT- $3^{\prime}$ for primers) was used as an internal standard, with the amplifying cycles of 30 .

Statistical analysis was done using the SPSS package (version 10.0; SPSS Company, Chicago, IL, USA). Mortality and edema rate were statistically compared between TCDD and control-DMSO using Chi-square test. For other time course experiment a $t$-test was employed to compare TCDD to DMSO at each time point independently, after ensuring homogeneity of variances between groups. For all experiments $p<0.05$ was used to determine significance.

\section{Results and Discussion}

To perform the experiment successfully, normally developing eggs were chosen, so the fertilization rate was regarded as $100 \%$. As in Fig. 1, mortality of the control and TCDD exposed group had fine discrimination at the first 180 hpf $(p<0.05)$. Embryos of the control went to a steadily developing stage after removing from their chorion and swimming for food, while the TCDD-treated embryos exhibited different types of developmental toxicity. Hence, the mortality of TCDD-treated embryos elevated and

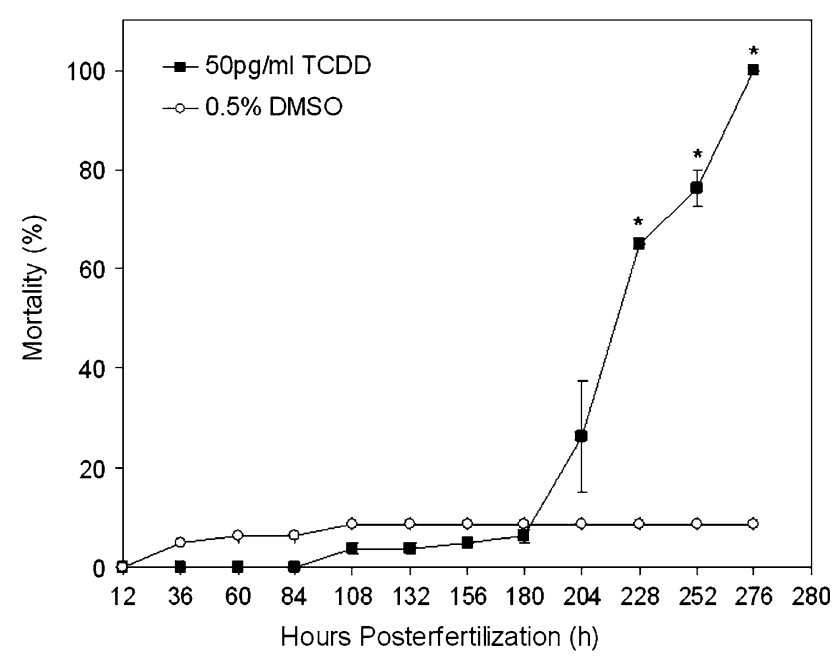

Fig. 1 Comparison of mortality between $0.5 \%$ DMSO-treated embryos and $50 \mathrm{pg} / \mathrm{mL}$ TCDD-treated embryos. After $72 \mathrm{~h}$ static exposure, embryos were transferred to aerating water for further observation. At the first $204 \mathrm{hpf}$, there was no significant difference between the control and the TCDD exposed group, where after TCDD-treated embryos decreased abundantly because of TCDD developmental toxicity. Each symbol represents the mean \pm SEM. *Significance compared to the equivalent stage embryos of control $(p<0.05)$ 


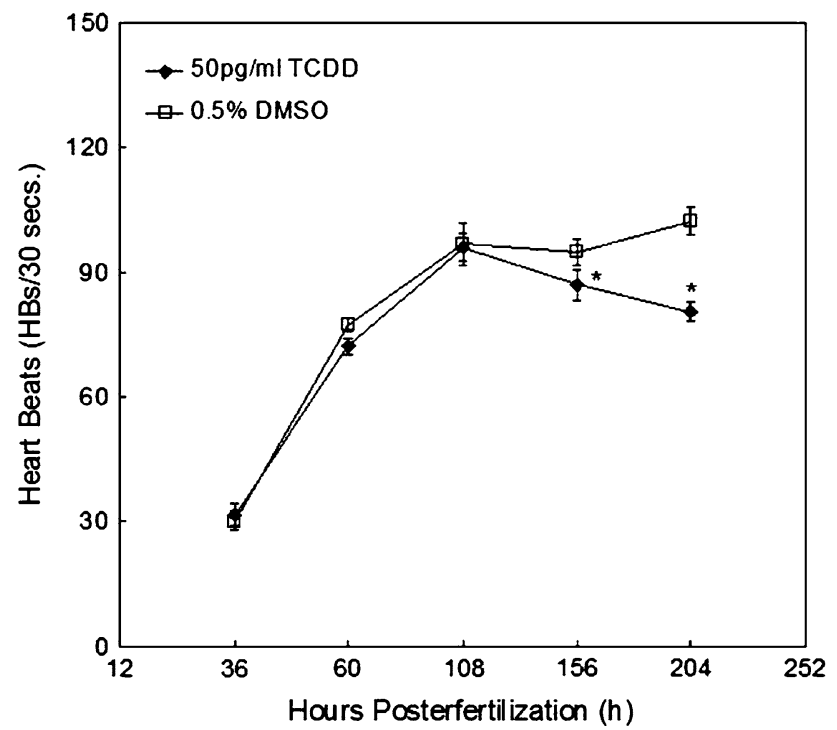

Fig. 2 Comparison of heart beats during a $30 \mathrm{~s}$ interval between $0.5 \%$ DMSO-treated embryos and $50 \mathrm{pg} / \mathrm{mL}$ TCDD-treated embryos $(\mathrm{n}=6)$. From $156 \mathrm{hpf}$, there were significant differences between the control and the TCDD-exposed embryos. After $204 \mathrm{hpf}$ heart beats decreased notably by TCDD, and the heart failed to palpitate till death (data was not expressed in this figure). Asterisks show significant difference from the equivalent stage embryos of control $(p<0.05)$ finally reached $100 \%$ at $276 \mathrm{hpf}$. The heart in zebrafish is the primary target apparatus for TCDD exposure, which is not only affected in morphology but also in its function (Antkiewicz et al. 2005), and in some extent the rate of heart can reflect the affection of blood flow. Results revealed that TCDD prominently weakened the heart rate of treated embryos compared to the control since $156 \mathrm{~h}$ (Fig. 2).

In this research, $50 \mathrm{pg} / \mathrm{mL}$, the relative lower exposure concentration of TCDD, not only weakened the heart rate but also caused serious edema to zebrafish (Fig. 3A). The edema rate was nearly $100 \%$ (Fig. 3B). Even though the yolk sac area of control decreased as embryo developed because of yolk absorption, the TCDD-treated yolk sac area elevated visibly (Fig. 3C). Correspondingly, from $144 \mathrm{hpf}$, TCDD significantly increased the pericardial area of treated embryos ( $p<0.05$, Fig. 3D). After $192 \mathrm{hpf}$ the yolk sac edema caused by TCDD was quite severe, so the pericardial edema of TCDD-treated embryos was relatively inconspicuous compared with the control.

As in Fig. 4A, in the mass, CYP1A mRNA expressions of the control were equivalent and kept a lower level through the whole three stages. Otherwise, at $52 \mathrm{hpf}$ no
A
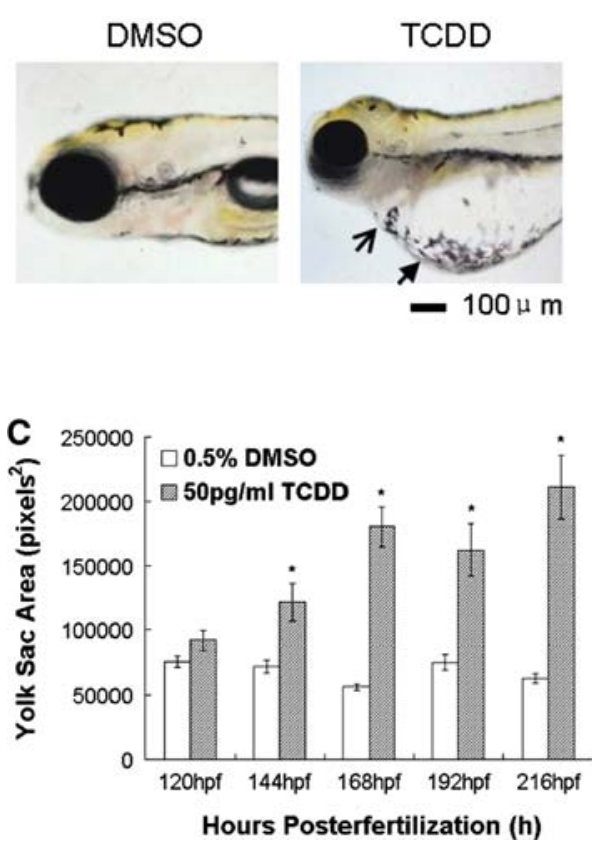

Fig. 3 Comparison of edema rate and edema area between $0.5 \%$ DMSO-treated embryos and $50 \mathrm{pg} / \mathrm{mL}$ TCDD-treated embryos at indicated time. (A) Photos illustrate a lateral view of edema severity. Void arrows indicate the pericardial cavity, and solid arrows represent the yolk sac edema compared to the control. (B) Edema rate. (C) The comparison of yolk sac area. From 144 hpf, edema severity of TCDDtreated group was rather significant. Yolk sac area of the control
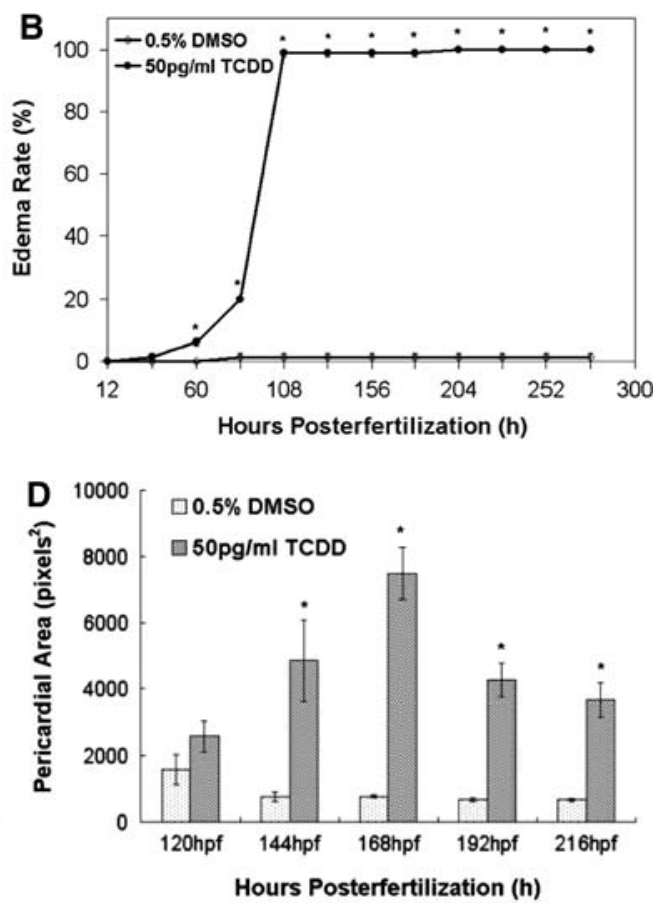

decreased due to nutrition. (D) The comparison of pericardial area. Also from $144 \mathrm{hpf}$, there was significant difference between the control and the TCDD-treated embryos. Each symbol represents the mean \pm SEM of five to eight embryos. Asterisks show significant difference between the same stages of control and TCDD-treated embryos $(p<0.05)$ 
difference was observed between the TCDD-exposed embryos and the vehicle in CYP1A mRNA expression, while it was obviously induced by TCDD at $96 \mathrm{hpf}$, but at $168 \mathrm{hpf}$ its expression level fell to the normal. On the other hand, there was no significant difference in RC mRNA expression at each selected time compared to the control (Fig. 4B).

Fish are particularly sensitive to chemical exposure, especially during early development (Walker and Peterson 1994). Zebrafish, as a prominent model vertebrate, was successfully applied to the toxicity investigation of TCDD.
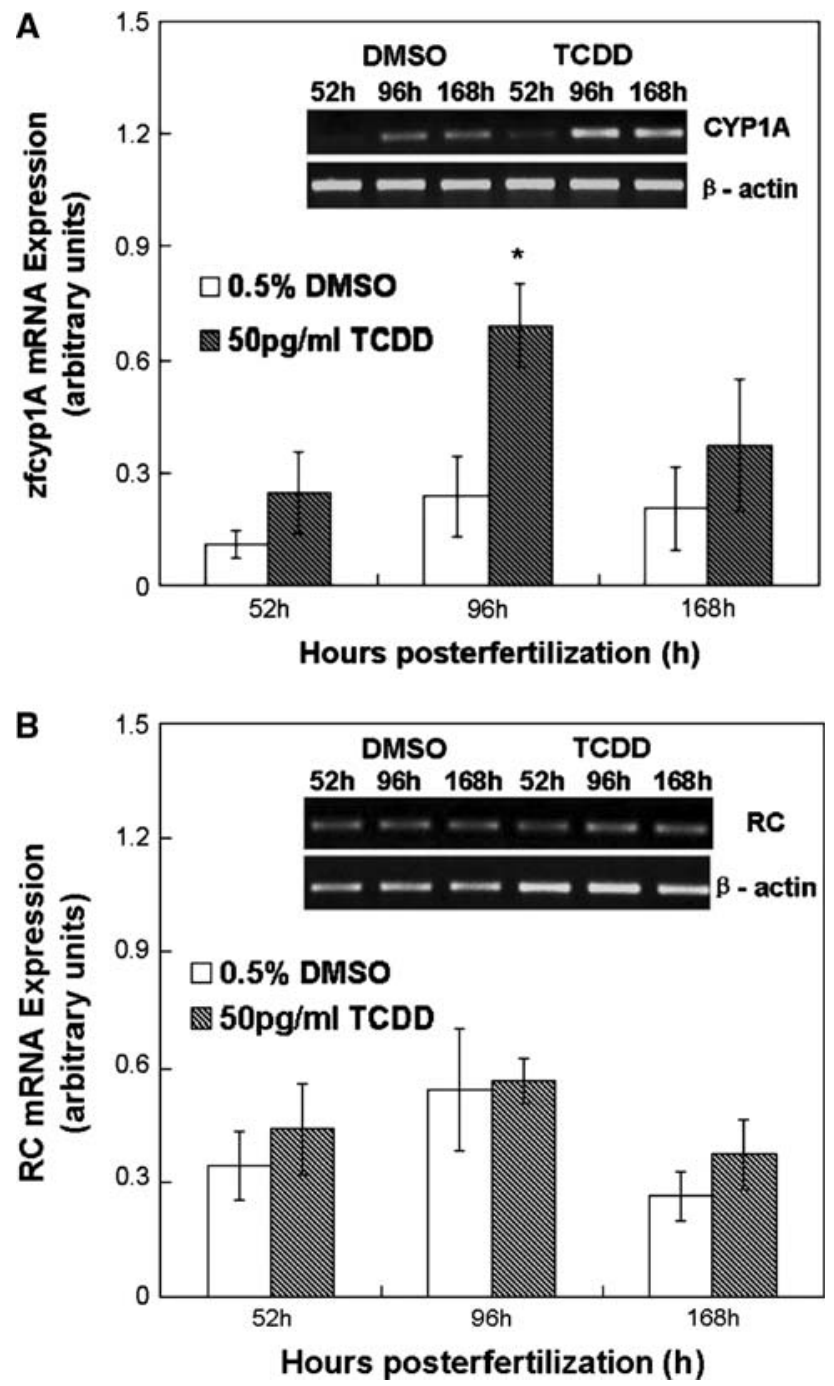

Fig. 4 Comparison of gene expressions between 0.5\% DMSOtreated embryos and $50 \mathrm{pg} / \mathrm{mL}$ TCDD-treated embryos at indicated time. (A) ZfCYP1A. The expression in the control was tiny, while the expression caused by TCDD was elevated significantly at $96 \mathrm{hpf}$ and decreased to lower levels at $168 \mathrm{hpf}$. (B) zfRC. There was no significant difference in RC mRNA expression at each selected time compared to the control. The insets were typical electrophoresis results. Values are mean \pm SEM of $n=4$. Asterisk indicates significant difference from equivalent stage embryos of control $(p<0.05)$
Most studies concerning TCDD waterborne exposure to zebrafish have been done at short-term and high doses exposure of dioxin (Antkiewicz et al. 2005; Prasch et al. 2004). Compared to those, we used a lower concentration of TCDD ( $50 \mathrm{pg} / \mathrm{mL})$ exposed to zebrafish statically for $72 \mathrm{~h}$ at its early stage, during which embryos could not swim. As described above, TCDD exposure caused mortality, severe edema and other toxicity endpoints to zebrafish embryos.

As is known now, edema is caused by two mechanisms: water barrier or/and decreased water export (Hill et al. 2004). Many factors are involved in the formation of edema, and some gene expressions are correlative. CYP1A is the best understood target gene (Nebert et al. 1990). TCDD causes a potent and sustained elevation of CYP1A mRNA expression (Andreasen et al. 2002) that precedes development toxicity of the different endpoints (Henry et al. 1997). However, people found TCDD caused developmental toxicity through a CYP1A-independent mechanism in zebrafish because the zfcypla-MO effectively prevented CYP1A up-regulation, but it did not prevent the signs of developmental toxicity, including pericardial edema, slowed blood flow, craniofacial malformation, and defects in erythropoiesis (Carney et al. 2004). In this research, CYP1A mRNA expression was investigated in three different periods: 52, 96, and $168 \mathrm{hpf}$. These three stages represented in, after and later of TCDD exposure, respectively. Results showed that CYP1A level in TCDD-treated group fell after a rise ultimately. The variety of CYP1A transcription paralleled with the TCDD exposure time, which reflected the bioaccumulation and metabolism of TCDD in vivo. The former results revealed that if exposure to TCDD is delayed until after $96 \mathrm{hpf}$, edema is not observed, which suggest TCDD interferes with cardiovascular and erythropoietic developmental processes that are normally completed by $96 \mathrm{hpf}$ (Belair et al. 2001). In this relatively low concentration of TCDD exposure, zebrafish embryos had no toxic symptoms at $52 \mathrm{hpf}$, while the CYP1A expression was also not affected. Later, with developmental toxicity occurring, TCDD began to produce its effect in vivo and induced CYP1A expression. Moreover, toxicity endpoints do not occur shortly after exposure, but takes place from $72 \mathrm{hpf}$ or later. This association is likely to explain why CYP1A level induced by TCDD has distinctness between 52 and $96 \mathrm{hpf}$. Then, at 168 hpf CYP1A mRNA expression in TCDD-treated embryos fell instead of maintaining its high level, which may also be related to TCDD depuration.

Also, the kidney is the most important organ for the homeostasis of water and electrolytes (Cao et al. 2003). Kidney dysfunction can lead to a loss of plasma proteins, such as albumin, in the urine. The hypo-osmotic effect in blood drives extracellular fluid out of the vasculature, 
leading to edema (Cao et al. 2003). RC has been demonstrated to have an inhibitory effect on various enzyme activation by $\mathrm{Ca}^{2+}$ and calmodulin in liver and kidney cells (Kurota et al. 1997; Yamaguchi and Mori 1990). In zebrafish embryo, TCDD exposure increased the intracellular calcium level, triggering $\mathrm{Ca}^{2+}$-mediated endonuclease activity leading to apoptosis (Dong et al. 2002). Our results indicated there was no significant difference in RC mRNA expression at each selected time compared to the control. Similarly, TCDD did not alter the abundance of RC transcripts or proteins in rat model (Pastorelli et al. 2006). So taken together, there may be some other $\mathrm{Ca}^{2+}$-regulated protein rather than $\mathrm{RC}$ which would be involved in TCDDinduced edema.

Through this experiment, it can be concluded that TCDD exposure with a relative lower concentration can cause severe toxicity endpoints to zebrafish embryos, especially the yolk sac and pericardial edema. Thus, further research at environmentally lower doses of TCDD exposure needs to be carried out.

Acknowledgments The authors are very grateful to National Natural Science Foundation of China (40332023), Wuhan Cheng-Guang Program for Young Scientists and Technicians (20055003059-11, 20065004116-23), and Natural Science Foundation of Hubei province (2005ABA134) for the funding during the study.

\section{References}

Andreasen EA, Spitsbergen JM, Tanguay RL, Stegeman JJ, Heideman W, Peterson RE (2002) Tissue-specific expression of AHR2, ARNT2, and CYP1A in zebrafish embryos and larvae: effects of development stage and 2,3,7,8-tetrachlorodibenzo- $p$ dioxin exposure. Toxicol Sci 68:403-419

Antkiewicz DS, Burns CG, Carney SA, Peterson RE, Heideman W (2005) Heart malformation is an early response to TCDD in embryonic zebrafish. Toxicol Sci 84:368-377

Belair CD, Peterson RE, Heideman W (2001) Disruption of erythropoiesis by dioxin in the zebrafish. Dev Dyn 222:581-594

Canga L, Paroli L, Blanck TJJ, Silver RB, Rifkind AB (1993) 2,3,7,8Tetrachlorodibenzo-p-dioxin increases cardiac myocyte intracellular calcium and progressively impairs ventricular contractile responses to isoproterenol and to calcium in chick embryo hearts. Mol Pharmacol 44:1142-1151

Cao ZJ, Tanguay RL, McKenzie D, Peterson RE, Aiken JM (2003) Identification of a putative calcium-binding protein as a dioxinresponsive gene in zebrafish and rainbow trout. Aquat Toxicol 63:271-282

Carney SA, Peterson RE, Heideman W (2004) 2,3,7,8-Tetrachlorodibenzo-p-dioxin activation of the aryl hydrocarbon receptor/ Aryl hydrocarbon receptor nuclear translocator pathway causes developmental toxicity through a CYP1A-independent mechanism in zebrafish. Mol Pharmacol 66:512-521
Cook PM, Robbins JA, Endicott DD, Lodge KB, Guiney PD, Walker MK, Zabel EW, Peterson RE (2003) Effects of aryl hydrocarbon receptor-mediated early life stage toxicity on lake trout populations in Lake Ontario during the 20th century. Environ Sci Technol 37:3864-3877

Curtis LR, Carpenter HM, Donohoe RM, Williams DE, Hedstrom OR, Deinzer ML, Bellsteln MA, Foster E, Gates R (1993) Sensitivity of cytochrome P450-1A1 induction in fish as a biomarker for distribution of TCDD and TCDF in the Willamette River, Oregon. Environ Scl Technol 27:2149-2157

Dong W, Teraoka H, Yamazaki K, Tsukiyama S, Imani S, Imagawa T, Stegeman JJ, Peterson RE, Hiraga T (2002) 2,3,7,8-Tetrachlorodibenzo-p-dioxin toxicity in the zebrafish embryo: local circulation failure in the dorsal midbrain is associated with increased apoptosis. Toxicol Sci 69:191-201

Guiney PD, Smolowitz RM, Peterson RE, Stegeman JJ (1997) Correlation of 2,3,7,8-tetrachlorodibenzo- $p$-dioxin induction of cytochrome P4501A in vascular endothelium with toxicity in early life stages of lake trout. Toxicol Appl Pharmacol 143:256273

Henry TR, Spitsbergen JM, Hornung MW, Abnet CC, Peterson RE (1997) Early life stage toxicity of 2,3,7,8-tetrachlorodibenzo-pdioxin in zebrafish (Danio rerio). Toxicol Appl Pharmacol 142:56-68

Hill AJ, Bello SM, Prasch AL, Peterson RE, Heideman W (2004) Water permeability and TCDD-induced edema in zebrafish early-life stages. Toxicol Sci 78:78-87

Kurota H, Yamaguchi M (1997) Activatory effect of calcium-binding protein regucalcin on ATP-dependent calcium transport in the basolateral membranes of rat kidney cortex. Mol Cell Biochem 169:149-156

Nebert DW, Petersen DD, Fornace AJ (1990) Cellular responses to oxidative stress: the $[\mathrm{Ah}]$ gene battery as a paradigm. Environ Health Perspect 88:13-25

Pastorelli R, Carpi D, Campagna R, Airoldi L, Pohjanvirta R, Viluksela M, Hakansson H, Boutros PC, Moffat ID, Okey AB, Fanelli R (2006) Differential expression profiling of the hepatic proteome in a rat model of dioxin resistance. Mol Cell Proteomics 5:882-894

Prasch AL, Heideman W, Peterson RE (2004) ARNT2 is not required for TCDD developmental toxicity in zebrafish. Toxicol Sci 82: $250-258$

Puga A, Hoffer A, Zhou S, Bohm JM, Leikauf GD, Shertzer HG (1997) Sustained increase in intracellular free calcium and activation of cyclooxygenase- 2 expression in mouse hepatoma cells treated with dioxin. Biochem Pharmacol 54:1287-1296

Schmidt JV, Bradfield CA (1996) Ah receptor signaling pathways. Annu Rev Cell Dev Biol 12:55-89

Takahashi H, Yamaguchi M (1997) Stimulatory effect of regucalcin on ATP-dependent calcium transport in rat liver plasma membranes. Mol Cell Biochem 168:149-153

Walker MK, Peterson RE (1994) Aquatic toxicity of dioxins and related chemicals. In: Schecter A (ed) Dioxins and health. Plenum Press, New York, pp 347-387

Westerfield M (1995) The zebrafish book. University of Oregon Press, Eugene, OR

Yamaguchi M, Mori S (1990) Inhibitory effect of calcium-binding protein regucalcin on protein kinase $\mathrm{C}$ activity in rat liver cytosol. Biochem Med Metab Biol 43:140-146 